\title{
The evolution and present status of the study on peak oil in China
}

\author{
Pang Xiongqi ${ }^{1,2 *}$, Zhao Lin ${ }^{1,2}$, Feng Lianyong ${ }^{1,2}$, Meng Qingyang ${ }^{1,2}$, \\ Tang $\mathrm{Xu}^{1,2}$ and Li Junchen ${ }^{1,2}$ \\ ${ }^{1}$ China University of Petroleum, Beijing 102249, China \\ ${ }^{2}$ Association for the Study of Peak Oil \& Gas-China, Beijing, 102249, China
}

\begin{abstract}
Peak oil theory is a theory concerning long-term oil reserves and the rate of oil production. Peak oil refers to the maximum rate of the production of oil or gas in any area under consideration. Its inevitability is analyzed from three aspects. The factors that influence peak oil and their mechanisms are discussed. These include the amount of resources, the discovery maturity of resources, the depletion rate of reserves and the demand for oil. The advance in the study of peak oil in China is divided into three stages. The main characteristics, main researchers, forecast results and research methods are described in each stage. The progress of the study of peak oil in China is summarized and the present problems are analyzed. Finally three development trends of peak oil study in China are presented.
\end{abstract}

Key words: Peak oil, oil resources, forecast model, trends of study

\section{Description of peak oil}

\subsection{Concept of peak oil}

Crude oil is a non-renewable resource. At the initial stage of oil field development, oil production increases and after the cumulative production exceeds a specific ratio of the ultimate recoverable reserves, oil production will begin to decline. The decline rate will differ according to the geological features and production methods of oil fields. It means that oil resources will follow a natural process of rise-grow-maturedecline. This can be portrayed as the life cycle of a limited system. Peak oil is the maximum point of oil production in oil fields caused by the limit of oil resources. The oil depletion process will lead to a series of economic, political and social issues. The main contents of peak oil study include resources evaluation, oil peak forecast, consequent political, economic and social problems and opportunities. Study of peak oil is significant for resource conservation, environment protection and sustainable development.

\subsection{Inevitability of oil peak}

\subsubsection{Rule of nature}

From the view of philosophy, everything follows a natural process of "rise-grow-mature-decline". Even the sun and our planet have their life cycles, and will decay eventually. Organisms begin to grow by exponential increase because of cell divisions. But due to environment limits, the rate of increase slows. Therefore it will reach the maximum and

\footnotetext{
* Corresponding author. email: pangxq@cup.edu.cn Received April 14, 2008
}

then begin to decline. Basically the process is non-linear, especially for the limited natural resources of fossil fuels formed in geologic eras.

\subsubsection{Limitation of resource}

Logically, the oil and gas resources in the world are limited. Though the oil discovered so far comprises only a part of the whole, oil is a non-renewable resource. The amount of initial oil in place is objective and limited, which results in the peak level of production and the time of peak production of each oil field or oil region.

\subsubsection{Reality}

In reality, 63 countries in the world have passed their oil peak already, including USA, UK, Norway and so on. There are also 35 countries very close to their oil peaks (Smith, 2006). There will be more countries reaching oil peak over time, resulting in the coming of the global oil peak.

\section{Influence factors and their mechanisms}

\subsection{Resource determines its discovery peak}

The resource determines its discovery peak and then affects the oil and gas production peak. In Fig. 1, $Q_{\mathrm{i}}$ means total resource, $q_{\mathrm{emax}}{ }^{i}$ means peak discovery and $Y_{\mathrm{i}}$ means peak discovery time. Under the same technical conditions, the larger the total resource, the later the discovery peak arrives.

The total resource is definite and objective. The forecasts of various experts at different times differ greatly (Fig. 2). These depend on people's understanding and interpretation of the formation and distribution patterns of oil and gas resources and the ability to exploit them. With the advancement of technology and ongoing exploration the discovered oil resources are increasing continually. 


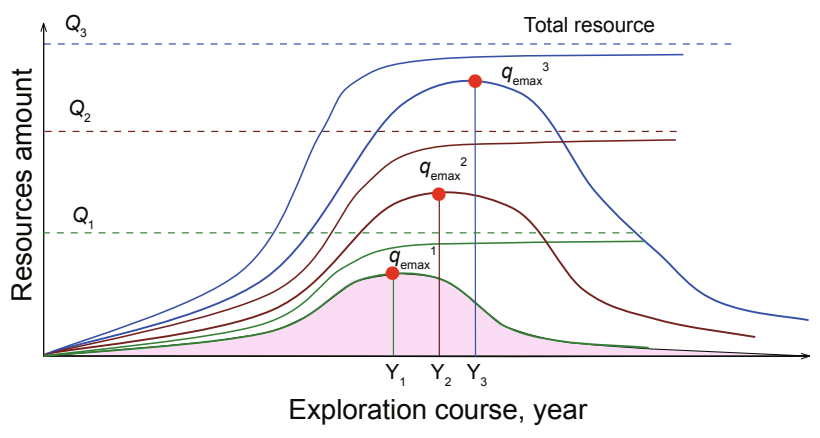

Fig. 1 Relationship between resource and its discovery peak

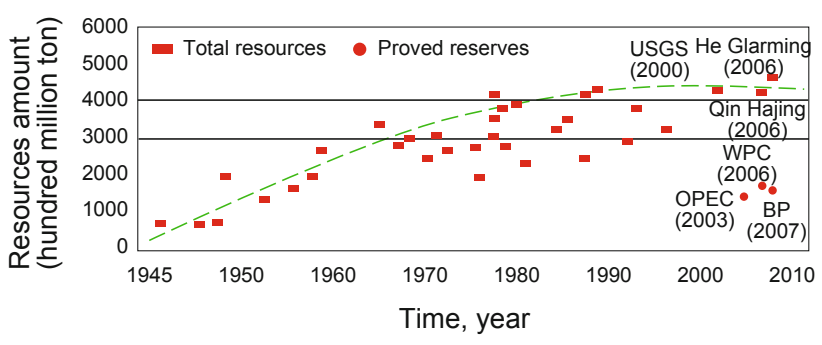

Fig. 2 Increase of evaluation result of initial world oil resources at different times

Source: Data collected from evaluation during the 12th -18 th world oil conference

\subsection{Resource discovery rate controls discovery peak}

The rate of resource discovery controls the discovery peak and then affects the production peak. In Fig. 3, $K_{\mathrm{e}}$ means the discovery ratio, $Q_{\mathrm{e}}$ means discovered resource. Given the total resource, the larger the rate of resource discovery is, the earlier the discovery peak arrives.

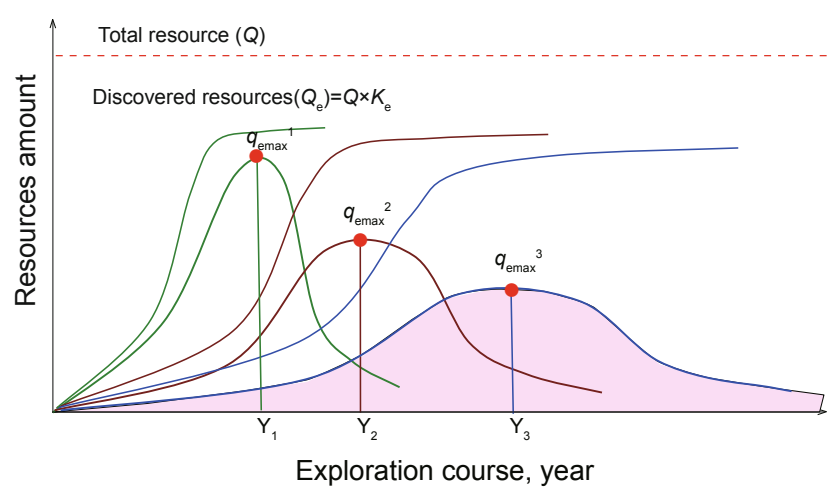

Fig. 3 Relationship between rate of discovery and discovery peak

The rate of resource discovery is determined by the amount of effort devoted to exploration and the level of exploration technology. Generally speaking, the more the effort and the higher the technical level, the higher the rate of resource discovery and the higher the discovery ratio.

\subsection{Discovery peak determines production peak}

As shown in Fig. $4, Q_{\text {er }}$ means recoverable reserve,
$Q_{\mathrm{P}}$ means cumulative production and $q_{\mathrm{pmax}}$ means peak production. The earlier the discovery peak is, the earlier the oil and gas production peak arrives, with about 20-40 years lag time.

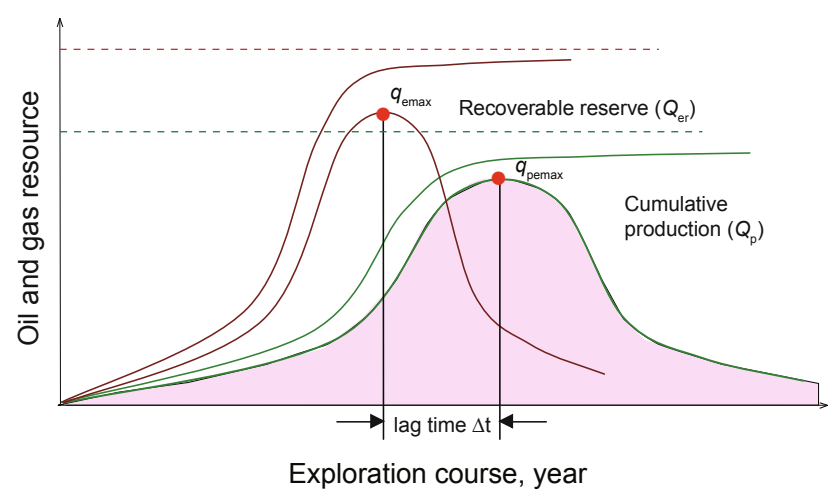

Fig. 4 Relationship between peak discovery and peak production

The discovery peak is determined by the effort devoted to exploration and the exploration technology in use. Generally speaking, the more effort we put in and the more sophisticated the exploration technology is, the earlier the discovery peak arrives. The lag time lies on the reserve-to-production ratio and the social demand for resources, which differ significantly at different areas. For example, the time lag between peak discovery and peak production in the Lower 48 States of USA is 35 years, while Norway is 27 years (Aleklett, 2006).

\subsection{Reserve depletion rate determines peak production}

If the resource discovery rate and total resource are given, the reserve depletion rate determines peak production (Fig. 5). The larger the reserve depletion rate is, the earlier the time of peak production arrives. The oil and gas reserve depletion rate is determined by the effort devoted to production and level of production technology. The more the effort devoted to production and the higher the technical level used, the earlier the production peak is reached.

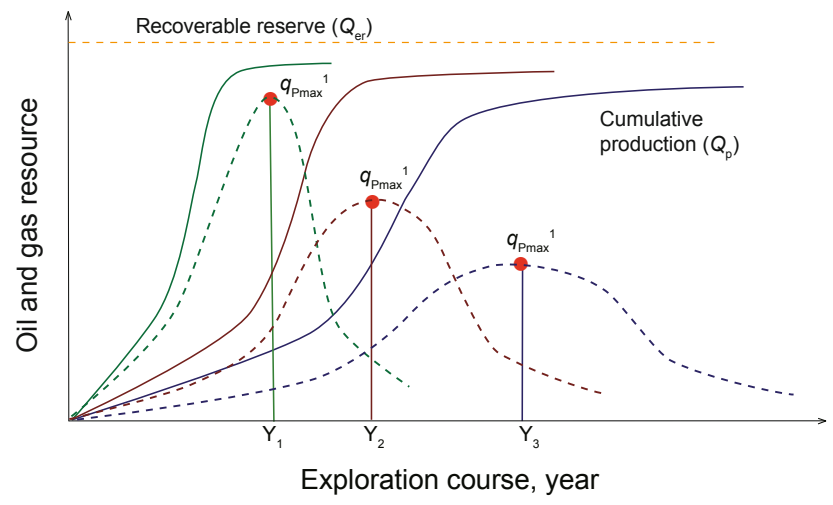

Fig. 5 Relationship between reserve depletion rate and peak production 


\subsection{Key factors control production peak}

The interrelationship of key factors controlling production peak is shown in the following mathematical model and Fig. 6.

$$
\left\{\begin{array}{l}
\int_{0}^{T} q_{\mathrm{p}}=Q_{\mathrm{p}} \\
Q_{\mathrm{er}}=Q_{\mathrm{e}} \times K_{\mathrm{r}} \\
Q_{\mathrm{e}}=Q \times K_{\mathrm{e}} \\
d_{\mathrm{i}}=q_{\mathrm{p}}+q_{\mathrm{i}}
\end{array}\right.
$$

where $q_{\mathrm{p}}$ means annual oil production, $Q_{\mathrm{p}}$ means cumulative production, $Q_{\mathrm{er}}$ means recoverable reserve, $Q_{\mathrm{e}}$ means discovered resource, $K_{\mathrm{r}}$ means recovery factor, $Q$ means total resource, $K_{\mathrm{e}}$ means discovery ratio, $d_{\mathrm{i}}$ means oil consumption, $q_{\mathrm{i}}$ means oil import.

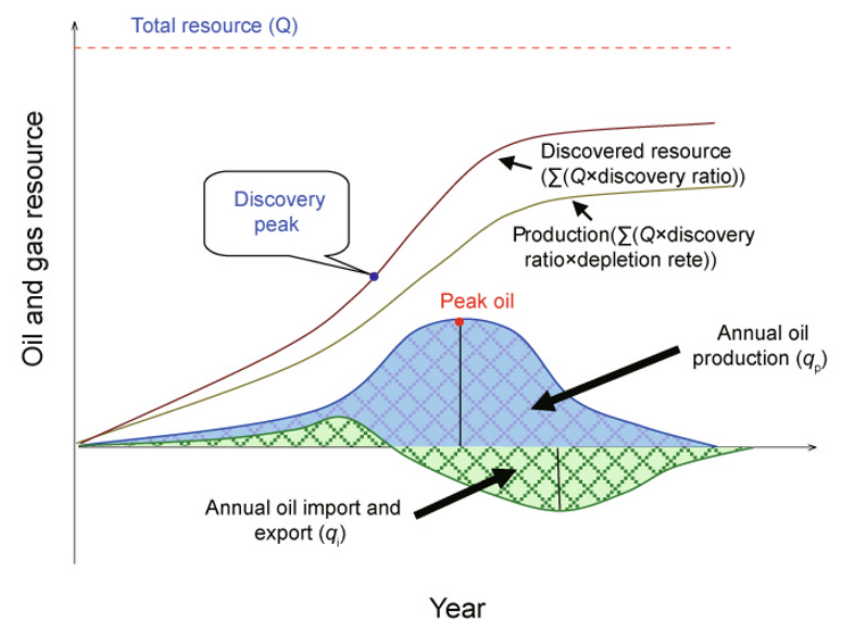

Fig. 6 Association between key factors of peak oil

As shown in Fig. 6, the oil peak is mainly controlled by the resource, the discovery ratio and the reserve depletion rate. The relationships among these factors are as follows: (1) Oil is a non-renewable and limited resource. (2) The discovered resource is the total resource multiplied by the current discovery ratio. With advances in petroleum geology and ongoing exploration, the discovery ratio will become higher. The discovered resource to date will tend to increase with time but of course it can never exceed the total resource. The discovery ratios of oil and gas at present in China are about $38 \%$ and $23 \%$ respectively, but the ratios in USA are $70 \%$ and $64 \%$ respectively, much higher than that in China (Zhang and Jia, 2007). (3) The recoverable reserve is the discovered resource multiplied by the recovery factor. The average recovery factor of China's developed oil fields at present is only about $30 \%$, and that of western countries is about $50 \%$. (4) Under the constraint of recoverable reserves in a country or region, its oil production will reach its peak. (5) If oil supply is more than sufficient to meet domestic demand, oil can be exported; otherwise, imports will be needed. Thus the oil demand of the country is satisfied by both domestic oil production and imported oil. It needs to be mentioned that there are also limits on the amount of oil that countries will be able import in future given limited global reserves and production.

\section{Advances in the study of peak oil in China}

\subsection{The stages of peak oil study in China}

We divide the advances in the study of peak oil in China into three stages. The research details are shown in Table 1.

\subsection{Progresses of China's peak oil study}

\subsubsection{Weng model}

Weng Wenbo, an academician of Chinese Academy of Sciences, contributed pioneering work to China's peak oil study. He published his monograph "The Foundation of the Forecasting Theory" in 1984 (Weng, 1984), in which he stated the natural process "rise-grow-mature-decline" of everything in the world. The development of oil and gas also follows such a pattern. He also proposed using the Poisson Cycle on the basis of this theory. As the first forecast model

Table 1 Stages of peak oil study in China

\begin{tabular}{|c|c|c|c|c|}
\hline Stages & Time & Main characteristics & Representatives & Representative results \\
\hline Initial stage & 1984-1996 & $\begin{array}{l}\text { The peak oil forecast model which was } \\
\text { proved to be applicable to forecasting } \\
\text { oil and gas reserves and productions in } \\
\text { China was proposed. }\end{array}$ & $\begin{array}{l}\text { Weng Wenbo (Weng, 1984), } \\
\text { Zhao Xudong (Zhao, 1987) }\end{array}$ & Weng Model \\
\hline $\begin{array}{l}\text { Developing } \\
\text { stage }\end{array}$ & 1996-2004 & $\begin{array}{l}\text { A series of forecast models were put } \\
\text { forward and more researchers devoted } \\
\text { to extended research. }\end{array}$ & $\begin{array}{c}\text { Chen Yuanqian (Chen, 1996; } \\
\text { 2003; Chen and Hu, 1995; 1996), } \\
\text { Wan Jiye (Wan, 2000), } \\
\text { Shen Pingping (Shen et al, 2000) }\end{array}$ & $\begin{array}{l}\text { I. The theoretical deduction of } \\
\text { peak oil models was done. } \\
\text { II. The linear iterative trial and } \\
\text { error method was put forward to } \\
\text { solve peak oil models. }\end{array}$ \\
\hline $\begin{array}{l}\text { Deepening } \\
\text { stage }\end{array}$ & 2004- & $\begin{array}{l}\text { Peak oil concept was introduced to } \\
\text { China through international academic } \\
\text { exchanges and the multi-cyclic, multi- } \\
\text { factors models which greatly enhanced } \\
\text { the research level were under study. }\end{array}$ & $\begin{array}{l}\text { Zhou Zikang (Zhou et al, 2005), } \\
\text { Pang Xiongqi (Pang et al, 2005), } \\
\text { Zhang Yongfeng (Zhang and Jia, } \\
\text { 2007), } \\
\text { Feng Lianyong (Feng et al, 2006; } \\
\text { 2007; 2008) }\end{array}$ & $\begin{array}{l}\text { Peak oil was formally introduced } \\
\text { to China. Peak oil forecast models } \\
\text { were categorized and the research } \\
\text { was extended and deepened. }\end{array}$ \\
\hline
\end{tabular}


for predicting medium to long-term reserve and production of oil and gas, it is called the Weng model. This model can be applied to forecasting the oil production of any oil region, or country. Mr. Weng published his English version "Theory of Forecasting" in 1991(Weng, 1991). In this book, the Poisson cycle was renamed as the life cycle. Zhao Xudong (Zhao, 1987) proved that the Weng life cycle model was feasible in forecasting the production and ultimate reserve using the example of more than 150 oil fields both in China and abroad.

\subsubsection{Theoretical deduction and solution of forecast models}

After Weng, more scholars developed their models. Chen Yuanqian (Chen, 1996) made a considerable contribution. He finished the theoretical deduction of forecast models and developed the linear iterative trial and error method to solve model parameters (Chen and $\mathrm{Hu}, 1996)$. A series of models were put forward by other scholars, such as Weibull model (Chen and Hu, 1995), HCZ model (Hu et al, 1995), Rayleigh model (Yuan and Chen, 1996), t model (Huang et al, 1987), etc. There are also a series of academic papers and monographs published.

\subsubsection{International academic exchange for extending and deepening research}

Pang Xiongqi (Pang et al, 2005), Feng Lianyong (Feng et al, 2006; 2007; 2008) and others formally introduced peak oil theory to China through international academic exchanges. The forecast models were categorized into three types: life models based on the limited life system, random models based on the theories of probability and statistics, and generalized mathematical models based on actual production

Statistical analysis of peak oil production

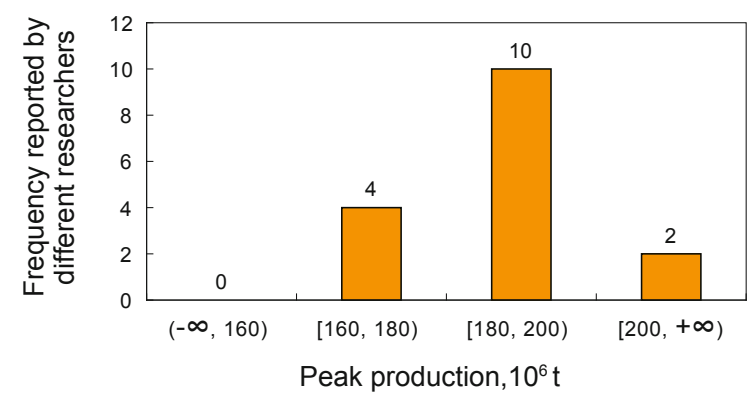

Statistical analysis of peak gas production

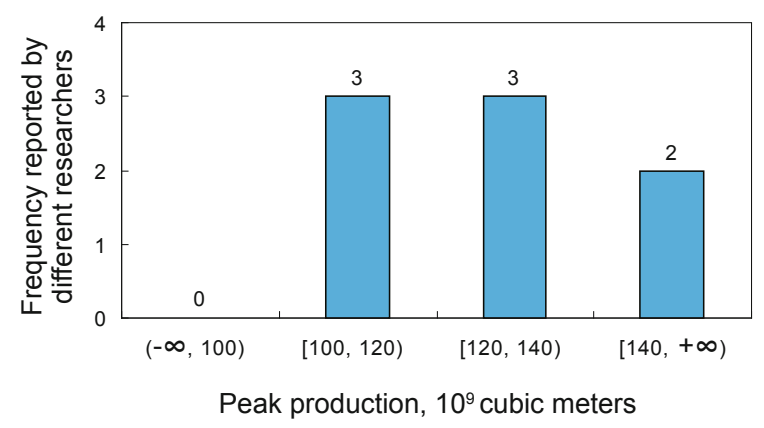

and logical reasoning. They also began to research the multicyclic, multi-factors model, which greatly enhanced the research level.

\subsubsection{Different conclusions by different scholars and their} cognition of convergence

Many scholars in China have undertaken research into China's oil peak, but each one has his or her individual conclusions due to different considerations and different models. The research conclusions are summarized as follows:

(1) Take direct or indirect trend extrapolation according to historic reserve or production data. Guo Baoshen (Guo and Li, 1997), Hu Chaoyuan (Hu, 1999), Yu Qitai (Yu, 2002), Chen Yuanqian (Chen, 2003), Zhou Zongying (Zhou, 2003), Feng Lianyong (Feng et al, 2006; 2007; 2008).

(2) Forecast by using the inter-restrictive relationship between resource, reserve and production, as Wan Jiye (Wang, 2000).

(3) Forecast by analogy with other regions or countries, as $\mathrm{Hu}$ Chaoyuan (Hu, 1999) and Zhang Yongfeng (Zhang and Jia, 2007).

(4) Making comprehensive analysis based on former research results, as Shen Pingping (Shen et al, 2000) Jia Wenrui (Jia et al, 2003), Mou Shuling (Mou, 2004), Yang Xueyan (Yang et al, 2006) and Energy Watch Group (2007).

Table 2 summarizes the research results on China's oil peak by different scholars at different times.

Fig. 7 is the statistical analysis of peak oil research forecasts by different scholars.

From Fig. 7, we can see that although the research conclusions by different scholars differ significantly due

\section{Statistical analysis of peak oil time}

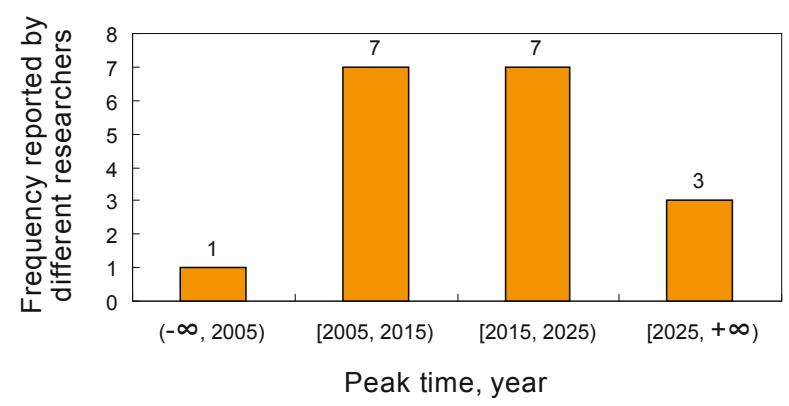

Statistical analysis of peak gas time

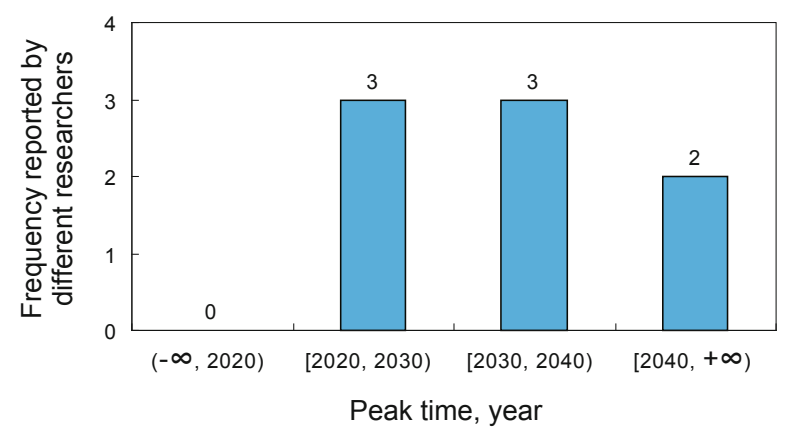

Fig. 7 Summary of forecasts from different scholars of the level of peak oil and peak gas production in China and the times of peak production, from Table 2 
Table 2 Analysis and comparison of the research results on China's peak oil by different scholars at different times

\begin{tabular}{|c|c|c|c|c|}
\hline \multirow{2}{*}{ Researchers } & \multirow{2}{*}{ Publication time } & \multicolumn{2}{|c|}{$\begin{array}{c}\text { Forecast result } \\
\text { (peak production/peak time) }\end{array}$} & \multirow{2}{*}{ Research characteristics or methodology } \\
\hline & & $\begin{array}{c}\text { oil } \\
\left(10^{6} \mathrm{t}\right) / \text { year }\end{array}$ & $\begin{array}{c}\text { Natural gas } \\
\left(10^{9} \text { cubic meters }\right) / \text { year }\end{array}$ & \\
\hline Guo Baoshen & 1997 & $191 / 2009$ & - & GM Model and Verhulst model \\
\hline Hu Chaoyuan & 1999 & - & $104-142 /-$ & $\begin{array}{l}\text { Method of exploitation rate curve of resource, } \\
\text { analogy method, Generalized Weng Model }\end{array}$ \\
\hline Shen Pingping & 2000 & $>200 /$ after 2020 & - & Comprehensive analysis \\
\hline Wan Jiye & 2000 & About $180 /$ after 2020 & About $100 /$ after 2020 & $\begin{array}{l}\text { "Resources amount -reserves-production" } \\
\text { balance control forecast model }\end{array}$ \\
\hline Yu Qitai & 2002 & $162.65 / 2002$ & - & $\mathrm{b}^{\mathrm{t}} \mathrm{t}^{\mathrm{c}}$ factor pattern growth curve \\
\hline Chen Yuanqian & 2003 & $164 / 2005$ & - & HCZ model \\
\hline Jia Wenrui, et al & 2003 & About 180/near 2010 & About 120/near 2035 & - \\
\hline Zhou Zongying & 2003 & $167-187 /$ near 2007 & - & Weng Model \\
\hline Mou Shuling & 2004 & $180-200 / 2020$ & $>150 /$ after 2020 & Comprehensive analysis \\
\hline Pang Xiongqi, et al & 2005 & $175 / 2010$ & $110 / 2026$ & Comprehensive analysis \\
\hline Yang Xueyan, et al & 2006 & About 180/ near 2007 & About 125/near 2034 & - \\
\hline Zhang Yongfeng, et al & 2007 & $190-236 / 2015-2037$ & - & $\begin{array}{l}\text { Analogy forecast model with resource } \\
\text { uncertainty }\end{array}$ \\
\hline Feng Lianyong, et al & 2007 & $185.38 / 2017$ & - & Generalized Weng Model \\
\hline Energy Watch Group & 2007 & About $187 / 2007$ & - & Comprehensive analysis \\
\hline Feng Lianyong, et al & 2008 & Abount 196/2026 & - & Generalized Weng Model \\
\hline $\begin{array}{l}\text { Comprehensive analysis } \\
\text { of this paper }\end{array}$ & 2008 & About 200/ 2026 & About $125 / 2035$ & Comprehensive analysis \\
\hline
\end{tabular}

to their various considerations and different models, the mainstream recognition is tending to be consistent, as shown in Table 3.

Table 3 Analysis of peak oil research results by different scholars

\begin{tabular}{ccc}
\hline Research item & Research results & $\begin{array}{c}\text { Mainstream } \\
\text { recognition }\end{array}$ \\
\hline Oil peak production, $10^{6}$ tons & $160 \sim 236$ & 190 \\
$\begin{array}{c}\text { Oil peak time, year } \\
\text { Gas peak production, } 10^{9} \text { cubic } \\
\text { meters } \\
\text { Gas peak time, year }\end{array}$ & $100 \sim 150$ & 2015 \\
\hline $2020 \sim 2050$ & 2037 \\
\hline
\end{tabular}

\subsection{Main problems in peak oil study in China}

\subsubsection{Emphasizing mainly on resource}

Chinese scholars study peak oil issues mainly from the perspective of oil and gas resources. Chen (2003), Guo and Li (1997) and Feng et al (2006; 2007; 2008) used the generalized
Weng model, HCZ model and Grey System mathematical model, respectively, to do indirect trend extrapolation by using the historic reserve and production data of oil and gas. Wan (2000) forecast oil and gas production based on the bilateral control and guarantee degree of resource, reserve and production. Zhang and Jia (2007) built the analogy model to forecast oil and gas production by contrasting the historic data of reserve additions and production increases between China and USA.

Actually modeling of oil peak forecasts is a giant complex system. Besides resource, oil peak is also controlled by many other factors, such as resource discovery ratio, reserve depletion rate, the effort devoted to exploration and production, and domestic and international oil demand. All variables interact and affect each other at the same time.

\subsubsection{All the recognitions reached under unstable circumstances}

The present Chinese economy is at an increasing and shifting period. Oil and gas demand usually increases dramatically when the industrialization and urbanization process is going on. In detail, China faces such unstable circumstances as follows. 
(1) Since 1990, China's energy demand has risen dramatically. As shown in Fig. 8, coal is still the main fuel in China's energy consumption even in 2006, while oil accounted for $20.4 \%$ and natural gas 3.0\%. During the industrialization and urbanization process, the energy mix is expected to change substantially.

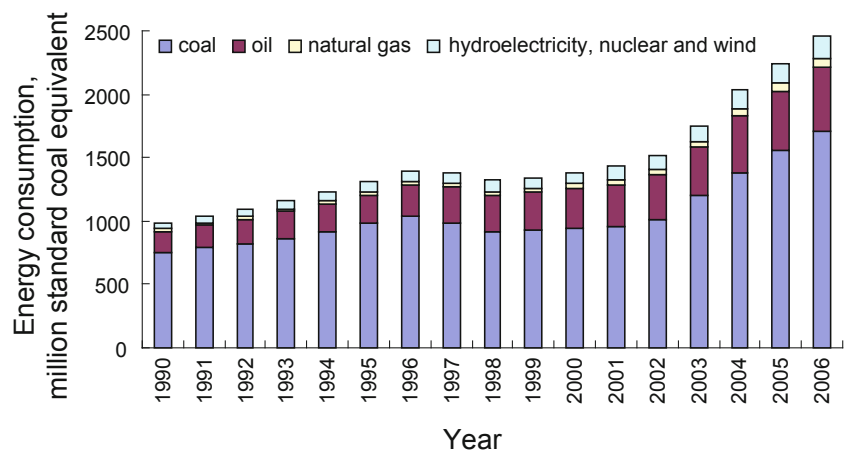

Fig. 8 Energy consumption mix in China

Data source: National Bureau of Statistics of China, 2007

(2) China has the largest population in the world. The oil consumption per capita is very low in China. As shown in Fig. 9, the oil daily consumption per capita in China is far less than that in USA, Japan, Germany and Australia. It is expected that the daily consumption per capita in China will increase greatly in the future.

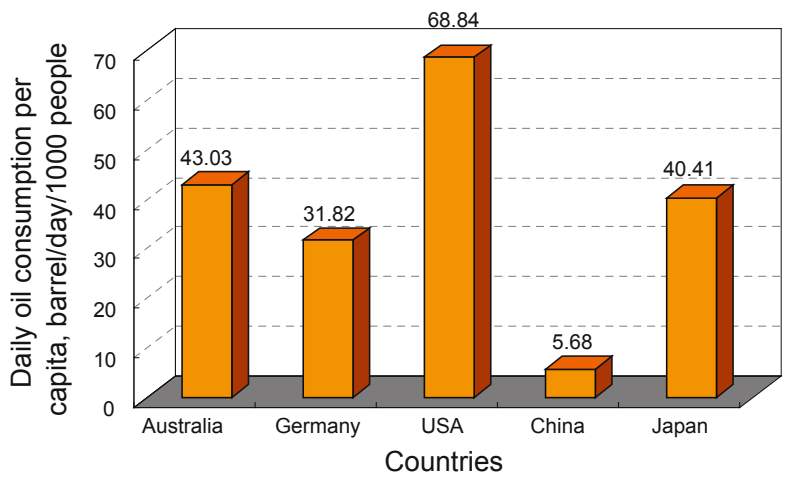

Fig. 9 Per capita daily oil consumption in different countries Data source: 2006 Population Reference Bureau's World Population Data Sheet and BP Statistical Review of World Energy (June 2007)

(3) China's reserve-to-production ratio for oil and gas is low (Fig. 10). Compared with the main oil and gas producing countries and the world average level, China's reserve-toproduction ratio for oil is only about 12 years and that for gas is about 41 years, which are much lower than the world average level.

(4) Domestic oil production of China goes only part of the way towards meeting the nation's demand. Many mature oilfields in east China have declined, and it has become harder and harder for increased production from new oilfields to make up for the decline in production from mature oilfields. At the same time, China needs more and more oil to
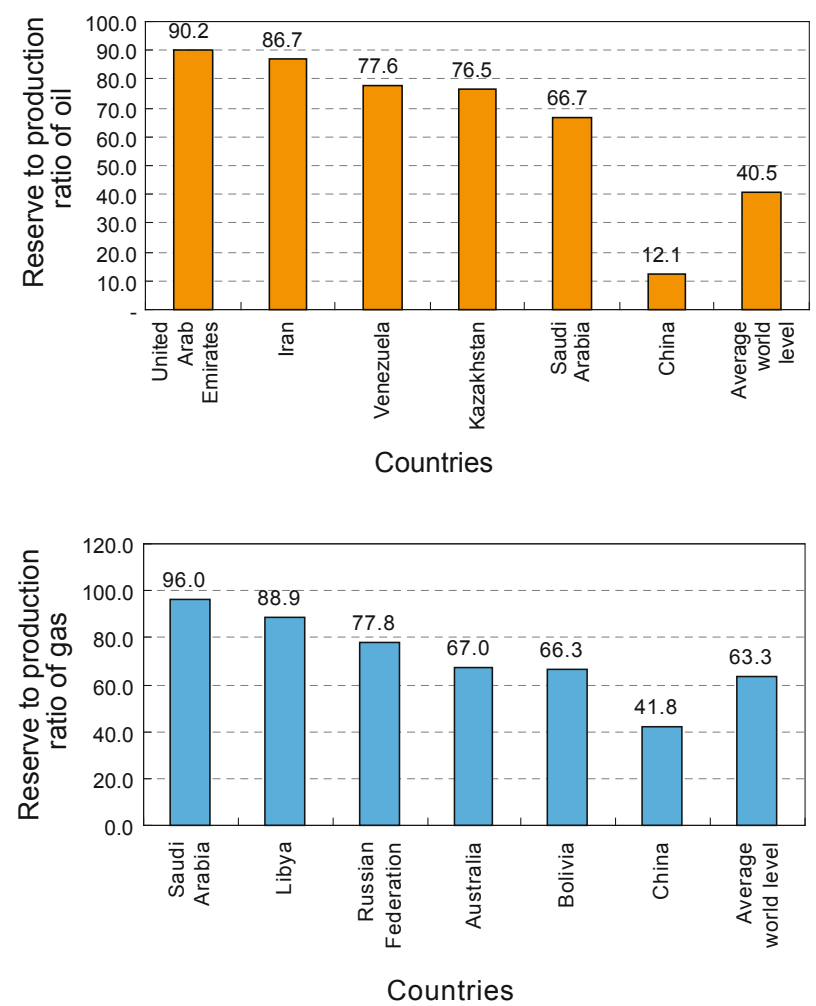

Fig. 10 Contrast of reserve-to-production ratio (in years) for oil and gas between China and other main oil and gas producing countries Data source: BP Statistical Review of World Energy, June 2007

support the fast growth of economy. China has been a net oil importer since 1993 and the volume of oil imported has been increasing rapidly since then (Fig. 11). China's net crude oil import in 2006 was 138 million tons, with the net oil products import of 24.01 million metric tons. China's increasing dependence on foreign oil is now about $47 \%$ of annual consumption.

All the forecasts of China oil peak are made based on the analysis of the current national situation. The oil peak forecast in such uncertainties needs to be analyzed before being utilized. With the increase of oil and gas utilization efficiency and the decrease of energy consumption per unit of GDP, the arrival of China's oil peak may perhaps be a bit later than the forecast time.

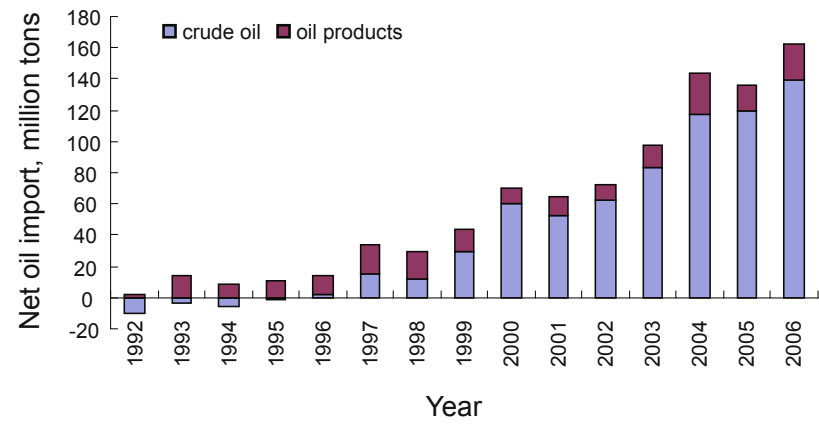

Fig. 11 Change of net oil import in China during 1992-2006 Data source: China National Custom Bureau, 2007 


\section{Trend of peak oil study in China}

The study of peak oil study in China is changing as follows:

(1) Shifting from forecasting peak resource discovery to peak production

The peak time of oil production is certainly later than that of resource discovery. The time of peak oil resource discovery in China was in 1961 when the supergiant Daqing oil field was discovered. After nearly 48 years, with the maturation of the main oil fields in east China, the oil fields in the western and central parts have become the strategic substitutes for oil from east China. China is facing more and more challenges in both the amount and the quality of its oil and gas resources. Forecasts of peak oil production are gradually being considered. More and more researchers have changed their attention from discovery peak to production peak.

(2) Shifting from forecasting peak oil to research into alternative energy

On the one hand, the coming oil peak means an inevitable decrease of oil production; on the other hand, oil as the lifeblood of modern industry is an indispensable source of energy and petrochemicals.

With the coming of the predicted peak time, peak oil research needs to shift from forecasting the oil peak to study of alternative energy sources. This includes developing new energy from more channels, searching for alternatives, regulating the consumption structure and trying to realize diversified supplies of energy. The research focus changes from predicting peak production and peak time to comprehensive study on conventional oil and gas resources, unconventional oil and gas resources, alternate energy and new energy sources.

(3) Shifting from searching for alternate energy to pursuing sustainable development

Firstly, the peak oil issue makes people aware of the scarcity of oil as a non-renewable resources. Secondly, adequate substitutes for oil, especially the substitute for petroleum-based vehicle fuels, face great technological and economic challenges, needing more time and effort. Thirdly, environmental pressure is increasing and environmental protection is becoming more and more severe and urgent. Research on alternate energy shifts to pursuing sustainable development in terms of energy, economy and environment. For example, the Chinese government has put forward a program of enhancing energy conservation consciousness, constructing a conservation-oriented society and developing socialized industrialization with low energy consumption.

\section{References}

Aleklett K. The Global Energy Supply Situation Today and Tomorrow. The Energy and Environment Conference. 2006. Shijiazhuang, Hebei, China

Chen Y Q. Derivation and application of the general Weng model. Natural Gas Industry Journal. 1996. 16(2): 22-26 (in Chinese)

Chen Y Q. Forecast on Future oil production and ultimate recoverable reserves in China. Forum of Petroleum Science and Technology. 2003. (2): 26-31 (in Chinese)

Chen Y Q and Hu J G. Review and new induction of Weng model. China
Offshore Oil and Gas (Geology) 1996. 10(5): 317-324 (in Chinese)

Chen Y Q and Hu J G. Weibull Model for predicting productions and ultimate reserves of oil and gas fields. Xinjing Petroleum Geology. 1995. 16(3): 250-255. (in Chinese)

Energy Watch Group. Crude Oil-the Supply Outlook. 2007. EWG-Series No. 3/2007.http://www.energywatchgroup.org/fileadmin/global/ pdf/EWG_Oilreport_10-2007.pdf

Feng L Y, Li J C, Zhao Q F, Pang X Q, et al. Forecast and analysis of China's oil supply and demand based on the peak oil model. Oil \& Gas Journal. January 14th, 2008: 43-47

Feng L Y, Zhao L, Zhao Q F, Wang Z M. Peak oil theory and forecast on world peak oil. Acta Petrolei Sinica. 2006. 27(5): 139-142 (in Chinese)

Feng L Y, Tang X and Zhao L. Reasonable planning of China's crude oil production based on the peak oil model. Petroleum Exploration and Development. 2007. 34(4): 497-501 (in Chinese)

Guo B S and Li H Y. Forecast on China's oil production in the initial 21st century. Geological Technology Management. 1997. (5): 51-53 (in Chinese)

Hu C Y. Initial Discussion on China's Oil and Gas Recoverable Reserves and Peak Production Forecast. 1999. 4(3): 1-5 (in Chinese)

Hu J G, Chen Y Q and Zhang S Z. A new model to predict production rate of oil and gas fields. Acta Petrolei Sinica. 1995. 16 (1): 79-86 (in Chinese)

Huang F S, Zhao Y S and Liu Q N.. A new model for oilfield performance prediction. Petroleum Geology \& Oilfield Development in Daqing. 1987. 6(4): 55-62 (in Chinese)

Jia W R, Xu Q and Wang Y L. Developing strategy of oil and gas industry under the aim of double GDP in 2020. China Energy. 2003. 25 (7):18-24 (in Chinese)

Mou S L. The oil and gas exploration and development strategy form: The perspective of present status and future development of China's oil and gas resources. Petroleum \& Petrochemical Today. 2004. 12(1): 7-9 (in Chinese)

Pang X Q, Meng Q Y, Bai G. P, Natori M and Zhang J. The challenge and countermeasures brought by the shortage of oil and gas in China. 2005. Presentation at ASPO-4, Lisbon Portugal

Shen P P, Zhao W Z and Dou L R. Prospect and future of China's oil and gas resources and forecast of increasing trend of oil production in the next decade. Acta Petrolei Sinica. 2000. 21(4):1-6 (in Chinese)

Smith M R. Resource depletion modeling and forecasting oil production. The 4th International Symposium on Hydrocarbon Accumulation and Petroleum Resource Evaluation. 2006. China University of Petroleum, Beijing, China

Wan J Y. The long and middle term oil and gas multi-development strategy in China. Resources Industries. 2000. Z1(3-4): 38-41 (in Chinese)

Weng W B. The Foundation of the Forecasting Theory. 1984. 79-86. Beijing: Petroleum Industry Press (in Chinese)

Weng W B. Theory of Forecasting. 1991. 80. Beijing: International Academic Publisher

Yang X Y, Luo H and Jia W R. Thinking on China's utilization of international oil resources. China Energy. 2006. 28(1): 6-10 (in Chinese)

Yu Q T. Forecast on oil production and recoverable reserves in China and USA. Xinjiang Petroleum Geology. 2002. 23(3): 224-228 (in Chinese)

Yuan Z X and Chen Y Q. Rayleigh model for predicting productions and ultimate reserves of oil and gas fields. China Offshore Oil and Gas (Geology). 1996. 10 (2): 101-105 (in Chinese)

Zhang Y F and Jia C Z. History contrast and analysis of oil reserves and production increase in China and USA. Research Report by Post-doctoral of Research Institute of Petroleum Exploration and Development, PetroChina. 2007 (in Chinese) 
Zhao X D. Forecast of life gross limited system by Weng Life Cycle Model. Chinese Science Bulletin. 1987. (18): 1406-1409 (in Chinese)

Zhou Z K, Wang S and Yang H. Simulation and analysis of the world oil peak year. Modernization of Management. 2005. (5): 10-12 (in

\section{Chinese)}

Zhou Z Y. Analysis of China's oil production status and developing potential. China Mining. 2003. 12(9): 4-7 (in Chinese)

(Edited by Zhu Xiuqin) 